\title{
Juan Antonio Lerdo de Tejada: las raíces regionales de una familia liberal, 1800-1850
}

Carmen Blázquez Domilnguez

\section{A manera de introducción}

$E_{\mathrm{n}}$ la actualidad se ha atribuido al estudio del siglo xix particular importancia para lograr interpretaciones más objetivas de problemas y fenómenos contemporáneos. Asimismo es evidente que muchos historiadores ya no consideran a esa centuria como una etapa "sencilla", en la que es fácil reconstruir o explicar hechos o factores que tuvieron lugar en ella. Por el contrario, las nuevas tendencias historiográficas han puesto de relieve que en el análisis de este lapso cronológico es más factible encontrar un conjunto de procesos de diversa índole, ocurridos en ámbitos regionales, que una "historia nacionalmente homogénea".

Quizás de aquí la insistencia que en los últimos años han mostrado los historiadores del siglo xIx para fijar su atención en espacios geográficos de menores dimensiones y preocuparse no tanto de interpretar los procesos nacionales, sino de verificar lo acaecido en los contextos regionales, de aceptar una diversidad de situaciones que necesariamente han conducido a un análisis más cauteloso de los procesos nacionales y a una mejor comprensión de lo que sucede en localidades pequeñas. ${ }^{1}$

Ocuparse de la historia regional es una exigencia para llegar al conocimiento y uso de historias mayores. Es una forma de romper el centralismo de algunas concepciones historiográficas y de recurrir a las alternativas locales, a las fuentes primarias (notariales, judiciales, parroquiales, particulares...) que permiten "hacer historia" desde nuevas perspectivas; comprender procesos que lleven a estudiar acontecimientos, factores y actores a veces entrelazados, a veces desconectados, con discrepancias y similitudes, características esenciales del siglo que nos ocupa. ${ }^{2}$

En el caso de Veracruz, la perspectiva regional y la localización y uso de fuentes primarias locales han indicado la necesidad de cuestionar diversos aspectos de la historia veracruzana del siglo xix, de dejar de lado las versiones tradicionales limitadas a proporcionar relaciones cronológicas en que acontecimientos y personajes no son objeto de reflexiones profundas. Muchas de las concepciones actuales son insufi-

\footnotetext{
'Mario Cerutti, Contribuciones recientes y relevancia de la investigación regional sobre la segunda parte del siglo XIX, ponencia del V Encuentro Nacional de Historia del Siglo xIX, Universidad Autónoma de Zacatecas, 27-29 noviembre 1986, p. 2 (versión mecanográfica).

${ }^{2}$ Ibid., p. 5. Aristides Medina Rubio, "Teoria, fuentes y método en historia regional", Relaciones. Estudios de Historia y Sociedad. Revista de El Colegio de Michoacán, Zamora, vol. IV, núm. 15, verano de 1985, p. 90-91.
} 
cientes para esclarecer circunstancias históricas locales, y las interrogantes sin respuesta exigen la búsqueda de explicaciones más amplias que permitan entender mejor los procesos sociales, económicos y políticos regionales en el trasfondo del contexto nacional.

Por ello nuestro interés en profundizar un aspecto de la historia regional, el relativo al surgimiento de nuevos grupos sociales que se van configurando en la primera mitad del siglo pasado, y que ejemplifican el dominio del capital comercial sobre la economía y la política locales, así como su paulatina asociación con las facciones políticas que pugnaban por implantar proyectos específicos de Estado y nación. Grupos cuyos integrantes comenzaron a aparecer en las postrimerias del siglo xvill con la práctica del comercio como herramienta fundamental para la paulatina acumulación de capitales.

Ahora bien, un estudio monográfico sobre Miguel Lerdo de Tejada, la información que posteriormente se ha localizado en los archivos municipales del puerto de Veracruz, Xalapa y Tlacotalpan, y en los notariales de esta última población y de la ciudad de México sobre el mismo personaje y varios miembros de su familia, y por último, la posibilidad de disponer de 107 cartas relacionadas con el comercio porteño escritas por el padre, Juan Antonio, encontradas en la Biblioteca Butler de la Universidad de Columbia, Nueva York, nos han permitido analizar el desarrollo de una familia veracruzana tradicionalmente considerada de filiación liberal y cuya praxis regional, vista a la luz de las nuevas tendencias historiográficas a las que hemos hecho referencia, refleja el surgimiento de un comerciante local, vinculado en forma muy estrecha al contexto colonial de finales del siglo xviII, que logró incorporarse a los nuevos grupos sociales surgidos a raiz de la Independencia, denominados de comerciantes-empresarios. Los hijos continuaron las actividades mercantiles y empresariales del padre, rebasaron el ámbito regional e ilustraron, en especial dos de ellos, Miguel y Sebastián, la vinculación con facciones políticas afines a sus intereses hasta quedar como representantes clásicos del grupo liberal que triunfó con la Reforma y la República restaurada.

Para principiar, señalaremos que los Lerdo de Tejada, al igual que otras familias locales también identificadas como familias liberales -podriamos agregar que tal vez sea también el caso de las calificadas de conservadoras-, se vieron sujetos a dos influencias determinantes: la inestabilidad política, social y económica de la primera mitad del siglo xIX y el caudillaje típico de la época. Con relación a la primera de dichas influencias, debe indicarse que una gran mayoría de los integrantes de la oligarquía regional, a la cual pertenecieron los personajes que se analizan, nacida entre los finales de la Colonia y el inicio de la etapa independiente, participó directa o indirectamente en las luchas por la conformación de un Estado y una nación. A lo largo de más de 50 años, la sociedad mexicana buscó una forma de organización, y del conflicto entre tendencias opuestas habría de originarse un estado crónico de disputas militares y sociales, crisis económica y guerras extranjeras cuyos efectos dejaron una huella profunda en la formación de las generaciones posindependientes.

La segunda influencia, el caudillaje, destaca la importancia nacional que tuvo para la oligarquía veracruzana la figura de Antonio López de Santa Anna. Es decir, la imagen santanista se ajustaba a una de las características del romanticismo del siglo xIX, la concepción de los hombres providenciales. Santa Anna, como caudillo, es el 
mejor ejemplo de dicha noción, de esa idea producto de la fusión de la fe en la providencia predicada por el cristianismo y el atavismo mágico de las culturas prehispánicas, que llevaba a esperar y a exigir "milagros" del "hombre providencial" sin reparar en su humanidad.

Por otro lado, el impacto que Antonio López de Santa Anna tuvo sobre los estratos locales privilegiados considerados parte de su "clientela" veracruzana debe analizarse tomando en cuenta que el mismo caudillo provenía de una familia criolla acomodada y que siempre conservó los vínculos creados por las relaciones familiares. La identificación de figuras clave de la sociedad regional, como es el caso de los Lerdo de Tejada, así como el examen detenido de la práctica política municipal y estatal, ponen de relieve-la vinculación entre los intereses de comerciantes, propietarios, hacendados y empresarios criollos y los intereses santanistas. ${ }^{3}$

Las dos influencias descritas estuvieron presentes en el desarrollo familiar de los Lerdo de Tejada. El padre, Juan Antonio, experimentó los efectos de la ruptura de la estabilidad novohispana desde el momento en que se planteó la crisis del viejo sistema colonial, cuando hubo de enfrentar, cada vez bajo mayor presión, la necesidad de adaptarse a nuevas circunstancias sociales, económicas y políticas.

\section{El inicio de un linaje}

Juan Antonio Lerdo de Tejada, español, originario de la provincia de Valladolid, fincó su residencia en el puerto de Veracruz a finales del siglo xvirl. Fue hijo legítimo de Juan Isidro Lerdo de Tejada y de María Concepción Matute y dejó su tierra natal para trasladarse primero a Cádiz, donde permaneció ocho años, y después a Nueva España. ${ }^{4}$ Durante su estancia en la población gaditana estuvo en estrecho contacto con un tío paterno, Francisco Lerdo de Tejada, individuo fuertemente involucrado en el movimiento mercantil colonial. Para 1800 ya se le identifica como comerciante porteño, y en 1807 había contraído matrimonio con Maria Concepción Corral y Bustillos, criolla nacida y aveciṇdada en la misma población, hija del coronel e ingeniero Miguel del Corral y de Maria Josefa Bustillos, y en posesión de un "cuantioso capital".s

En esta época, el puerto de Veracruz llevaba casi tres siglos de ser prácticamente el centro de los comerciantes españoles y el único punto de contacto entre Europa y Nueva España. De manera que Juan Antonio se desenvolvió dentro de una comunidad porteña cuya prosperidad se hallaba basada en la importancia de la población como centro del comercio novohispano. A pesar de que la insalubridad era una de sus mayores desventajas, a principios del siglo xIX Veracruz exportaba productos con un valor de 15 millones de pesos como promedio anual, y España seguía enviando mercaderías valuadas en 11 millones de pesos. Comerciaba con los pueblos de la provincia y

\footnotetext{
${ }^{3}$ Carmen Blázquez Dominguez, "El grupo liberal veracruzano del periodo juarista", Secuencia, Revista Americana de Ciencias Sociales del Instituto Dr. José Ma. Luis Mora, México, núm. 1, marzo 1985, p. 37.

4 Carmen Blázquez Dominguez, Miguel Lerdo de Tejada. Un liberal veracruzano en la politica nacional, México, El Colegio de México, 1978, p. 5. Frank A. Knapp, Sebastián Lerdo de Tejada. Xalapa, Universidad Veracruzana, 1962, p. 17.

${ }^{5}$ Archivo Notarial de Xalapa, Protocolo 1834, 15 mayo 1834 (en adelante se citará ANX). Carmen Blázquez Domínguez, "Miguel Lerdo de Tejada...", op. cit., p. 6. Frank A. Knapp, op. cit., p. 19.
} 
con los puertos de la costa del Golfo llevando efectos extranjeros y nacionales para recibir en cambio grana, harina, café, tabaco y frutas, ya fueran para el consumo de la ciudad, para exportarlos a otros puntos de la costa o para enviarlos al extranjero. El continuo movimiento mercantil y los diversos gravámenes impuestos al comercio provocaron el aumento del contrabando y la piratería, actividades que tanto el gobierno colonial como el peninsular trataron de impedir. Que su éxito fue relativo lo prueban las frecuentes representaciones del Consulado y de los comerciantes veracruzanos solicitando se tomaran las medidas necesarias para obstaculizar la acción de los piratas y la introducción del contrabando.

De manera que, en un principio, las actividades mercantiles de Juan Antonio Lerdo de Tejada se desenvolvieron ligadas a lo que se conoce como "pacto colonial" que, en términos generales, permitia a los países metropolitanos reservarse el monopolio mercantil de sus colonias, garantizándoles recíprocamente el mercado metropolitano. De igual forma sus operaciones dependían de la red de comunicaciones y transportes creada durante la época colonial, destinada a funcionar como parte de un sistema económico a larga distancia, basado en la exportación de materias primas y la importación de artículos manufacturados. ${ }^{6}$

Probablemente se requiera buscar otras fuentes primarias, tal vez españolas, para profundizar más en el alcance del movimiento mercantil de Juan Antonio, y conocer así, con mayor amplitud, sus relaciones dentro de la sociedad regional. Por ahora, y con el material disponible, pueden deducirse varias conclusiones en lo que se refiere a su desempeño como comerciante, su posición dentro de la sociedad regional y sus opiniones políticas.

La serie de cartas localizadas en la Biblioteca Butler nos habla del periodo que va de 1811 a 1817 . Todas las misivas iban dirigidas a Manuel de Urquiaga y su información es de gran riqueza. En términos globales, por los antecedentes que relatan, puede afirmarse que, al menos hasta 1810 , Juan Antonio Lerdo de Tejada se consideraba a sí mismo, como hemos indicado, comerciante con "capital cuantioso", desarrollsndo sus actividades en una época en que se gozaba de estabilidad y seguridad para el giro mercantil. Paralelamente al manejo de sus propios recursos, se encontraba vinculado, y en cierta forma dependiente, de su tío, Francisco Lerdo de Tejada, el comerciante de Cádiz de quien recibía gran parte de los efectos europeos con los cuales traficaba, a la vez que actuaba como consignatario de varios individuos de la ciudad de México, primordialmente del citado Urquiaga.

Los cargamentos que recibía de la península comprendían en primer término textiles de diversas clases (seda, paños, muselinas, tafetanes, sargas...), y en segundo, mercería (hilos, agujas, listones...), libros y abarrotes; de igual forma se ocupó de la venta de materias primas como fierro, estaño, seda en rama e incluso algodón. Las diferentes transacciones le permitieron crear una amplia red mercantil en donde no sólo se hallaban incluidos comerciantes porteños como

${ }^{6}$ Miguel Lerdo de Tejada, Apuntes históricos de la heroica ciudad de Veracruz..., 3 vols., México, Imprenta de Ignacio Cumplido, 1850; vol. 1, p. 129; vol. 3, p. 54. Ciro Cardozo (Coord.), México en el siglo XIX (1821-1910). Historia económica y de la estructura social, México, Editorial Nueva Imagen, 1983, p. 24. Peter Rees, Transportes y comercio entre México y Veracruz, México, SepSetentas, núm. 304, 1976, p. 11-15. 
Pablo Frayle y Santa María, Tomás Martínez, José Ignacio de la Torre, Félix de Aguirre, Francisco de Guerra y Agreda y Mariano Pasquel, sino capitalinos como el mismo Manuel de Urquiaga, Miguel Dacomba y Francisco Vélez de Escalante, y los poblanos Ramón Adalid y Joaquín Cardozo. Los nexos con grupos mercantiles se extendieron por la costa de Barlovento hacia Tuxpan y Tampico, para alcanzar, por aquella vía, algunos puntos de la región central de la Nueva España como Aguascalientes y Querétaro, hasta llegar a Guadalajara y Acapulco, practicando, además del comercio, la "habilitación" o el préstamo de diversas cantidades por medio del giro de libranzas. ${ }^{7}$

Las actividades descritas se continuaron llevando a cabo sin mayores dificultades hasta 1811 , en que la aparición del movimiento insurgente quebrantó la estabilidad y la seguridad coloniales. A partir de esta fecha y hasta 1817 (7 años), las cartas que Juan Antonio remitió a Urquiaga reflejaban todos los problemas derivados de una situación política distinta, al mismo tiempo que describían el sentir de la comunidad mercantil porteña. Para entonces, las dificultades de comunicación con España y con la ciudad de México se transformaron en la principal preocupación del sector mercantil; la incomunicación en que paulatinamente se halló el puerto de Veracruz repercutió con fuerza en el renglón económico local de mayor importancia, el comercio, y las referencias a ella, así como a los perjuicios causados por el acoso de las partidas insurgentes, están presentes en todas sus misivas.

De igual forma, Lerdo de Tejada dejó constancia de la inquietud de los comerciantes peninsulares por el desarrollo de los acontecimientos europeos, en especial por los derivados de la ocupación francesa de la península y que afectaban a sus centros de abastecimiento, reflejando que se vivía pendiente de las noticias traídas por los diversos nativos que tocaban la plaza porteña. ${ }^{8}$

Así, pues, el análisis de esta correspondencia facilita información de diverso tipo. Por ejemplo, Juan Antonio Lerdo de Tejada registró con bastante detalle el arribo de diferentes tropas españolas destinadas, supuestamente, a neutralizar la rebelión insurgente. En enero de 1812 comentó la llegada de 709 hombres del regimiento de Asturias y la esperanza de la oligarquía local de que, en un futuro próximo, el gobierno virreinal concentrara en el puerto de Veracruz entre 4 mil y 5 mil soldados, agregando que todo estaba dispuesto para su inmediato traslado a la ciudad de México: “. . . cuya noticia será a V.M. de tanto gusto como a nosotros en tan críticas circunstancias como nos hallamos..."9

En el mismo mes comentó lo bien "obsequiados" que se hallaban 100 artilleros, parte de las tropas recién llegadas, y que quedaban en la plaza porteña a disposición del Virrey:

... hoy tienen una gran comida en Santa Fe; es toda gente asturiana y joven, y la trompeta que usan impone terror, y así soldados como oficiales usan gorras a la moderna; su uniforme es del color de campaña y vuelta celeste. Como su entrada fue al anochecer, fueron hasta el cuartel rodeados de hachas de cera encendidas, y

${ }^{7}$ Lerdo de Tejada, Papers, 1811-1817, Rare Books and Manuscripts Library, Butler Library, Columbia University, Nueva York.

${ }^{8}$ Loc. cis.

${ }^{9}$ Ibid. 4 y 8 enero 1812 . 
entre mil vivas, siendo ayer un día de función con la revista que pasaron en la plaza. ${ }^{10}$

De manera similar registró, por las mismas fechas, la entrada de 800 hombres procedentes de varios regimientos españoles, que adoptaron el nombre de Primero de América, los cuales portaban uniforme azul, vuelta encarnada; para agosto señaló la de 1300 soldados de Galicia, 600 de los cuales fueron seriamente afectados por la insalubridad de la "tierra caliente"; y en abril del año siguiente, 1813, se alegró por el arribo de 2 mil elementos que habían salido de Cádiz. ${ }^{11}$

En realidad, la llegada de fuerzas militares peninsulares significaba para los comerciantes indianos que, en primer lugar, el gobierno español en funciones se preocupaba, a pesar de la guerra contra los franceses, por la situación de inestabilidad que imperaba en la Nueva España y, en segundo, la posibilidad de seguir ejerciendo el control político, lo que a su vez garantizaba la continuidad de su práctica mercantil con la misma seguridad de los años anteriores. En relación con las tropas desembarcadas en los primeros años de 1812 indicó: "... por lo que es visto que el gobierno se ha propuesto ir mandando tropas en todos los buques. .."12

Más adelante, en junio de 1814, cuando Napoleón fue desterrado y ascendió al trono francés Luis XVIII, escribió a Urquiaga diciendo:

Luego que se hizo la paz decretaron las Cortes 20 mil hombres para la América, desde luego este motivo origina la falta de buques de Cádiz que observamos, mas por tan plausibles sucesos todo lo podemos dar por bien empleado. Quiera Dios que en este reino podamos en breve disfrutar iguales satisfacciones. ${ }^{13}$

En consecuencia, esperó, como otros muchos comerciantes de la época, que dichas fuerzas mantuvieran libre de partidas insurgentes el sistema de comunicaciones de la región central de Veracruz, que garantizaran la libre circulación de hombres y efectos y que protegieran las conductas que bajaban de la capital y los convoyes que circulaban por las rutas de Xalapa, Córdoba y Orizaba, mientras continuaba desplegando actividades mercantiles y movilizaba capitales.

Entre 1811 y 1817 mantuvo un contacto estrecho con su tío Francisco, recibiendo de Cádiz cargamentos de diferentes efectos para Manuel y José María Urquiaga, este último llegado del puerto gaditano hacia 1815 , y para sí mismo, realizando sus operaciones con el Altiplano por la ruta de Xalapa o la de Tuxpan y Tampico. Tuvo a su cargo la movilización de fuertes capitales, giró libranzas por diferentes cantidades, prestó circulante en la modalidad de "habilitación", registró diversas cantidades de dinero propias o a nombre de otros para su salida a Europa, y practicó en el puerto de Veracruz las diligencias que requería su posición de consignatario, principalmente de los Urquiaga. ${ }^{14}$

${ }^{10}$ Ibid., 15 enero 1812.

"Ibid, 1 febrero y 1 agosto 1812,16 abril 1813.

${ }^{12} \mathrm{Ibid}, 11$ enero 1812 .

${ }^{13}$ Ibid, 3 junio 1814 .

${ }^{14} \mathrm{Ibid}$., diciembre 1811 , enero-febrero 1812 , abril 1813, marzo 1814 , febrero-marzo 1815, octubre-noviembre 1817. 
Sin embargo, a pesar de esa insistencia en comerciar como en tiempos normales, esperando que de alguna forma las autoridades virreinales y peninsulares resolvieran los problemas políticos que por estas fechas enfrentaba la Nueva España, la verdad fue que el ejercicio mercantil novohispano sí fue afectado por la guerra de Independencia y por los sucesos peninsulares. De manera que, paulatinamente, Juan Antonio Lerdo de Tejada tuvo serios apuros financieros, e incluso estuvo a punto de declararse en bancarrota. En varias de sus cartas se encuentran quejas constantes por la incomunicación, la falta de pago de las libranzas giradas y de los préstamos concedidos, el contrabando impulsado por los ingleses, la presencia de corsarios, la escasez de circulante en la plaza porteña, la tardanza de las conductas en bajar a la costa y la frecuencia con que los convoyes eran asaltados o descuidados. En enero de 1812 indicó a Urquiaga que “... aunque todos los arrieros han llegado, últimamente robaron uno por el Ojo de Agua de bastante consideración, y así no se puede pensar en poner nada en camino..."1s

En febrero del mismo año, al informar sobre el retraso de la partida del navio Miño hacia España, declaró:

... Dios quiera que con esta demora se resuelva baje la conducta que aquí vamos teniendo ya por una ilusión pues con las tropas que han bajado a Puebla podía muy bien haber venido, mas no se entienden las cosas dèl día. Hoy ha llegado una fragata inglesa que viene a continuar la burla que en todas partes están haciendo de nosotros, el menos mal es introducir cada una un buen contrabando, y así es que la grana en Londres vale menos que en Cádiz... ${ }^{16}$

Para abril de 1813 se quejaba de la falta de mercancías españolas, como la seda, por las malas noticias que de la Nueva España llegaban a la metrópoli, lo que hacía que

... vengan pocos barcos y pueda V.M. estar seguro que el comercio de Tampico no durará más que el preciso tiempo para transitar por tierra, pues ha ofrecido terribles pérdidas, entre otras falta desde diciembre una goleta con 450 mil pesos cuyo paradero se ignora... ${ }^{17}$

En marzo de 1814 tuvo problemas con el precio de los fletes, llegando a pagar 160 pesos por carga de ropa y 10 menos por la de mercería, y afirmaba:

... mientras duren estos malditos convoyes es imposible quedar uno bien, yo he llevado la idea de buscar arriero seguro y éstos le imponen a uno la ley a su antojo...

... por iguales motivos está casi concluido el giro de Tampico pues no es sufrible tanta pesadez; el año pasado uno de Durango se llevó de aqui más de 100 mil pesos puestos en una memoria y reclamado por los interesados contesta, que hasta que no venga en coche a Veracruz no quiere pagar a nadie. ${ }^{18}$

${ }^{16}$ Jbid., 26 febrero 1812.

${ }^{17}$ Ibid., 3 abril 1813 .

${ }^{18}$ Ibid., 2 marzo 1814. 
Y los problemas con los arrieros también fueron constantes, sobre todo porque no estaban dispuestos a asegurar la entrega de las cargas. En relación con el arriero Antonio Villeda dijo:

Me tienen lleno de pesar las desgracias con Villeda, y este ejemplar hace de necesidad que su remesa sea fletando V.M. arriero en un todo, cosa que yo no tenga que hacer otra cosa que entregarle arreglado a su orden, pues por diversas consideraciones... hacen en mi imposible volver a exponer mi honor en circunstancias tan extraordinarias. .. 19

Los obstáculos cada vez mayores que se encontraban para la práctica mercantil lievaron a Juan Antonio a dos decisiones. Primero eligió vender los productos más importantes que tenía, como la seda, en el mismo puerto de Veracruz, sin hacerse responsable por su traslado a la ciudad de México. Y más adelante, a mediados de 1814 , resolvió no recurrir más a la arriería:

Por la desgracia con Villeda he resuelto no volver a fletar un tercio de mis asuntos particulares hasta que no se camine como el año de 1810 y por lo que respecta a los de V.M., así como para los que tengo como para los que pueda recibir, siempre que haya convoy V.M. fletará en esa arriero o arrieros que guste le lleven su carga... Yo no volveré a exponer mi opinión a tantas violencias y zaragates de que se componen los convoyes... ${ }^{20}$

El hecho de que los intereses mercantiles se vieran tan seriamente afectados, y las vinculaciones que se tenían con el sistema político colonial, hicieron que, al menos en el puerto de Veracruz, una gran parte de los comerciantes no se mostraran inclinados a apoyar el movimiento insurgente, y que imperara entre ellos un clima de esperanzas y alegrías cuando se tenían noticias relativas a los fracasos rebeldes. En 1812 Juan Antonio Lerdo de Tejada comentó a Urquiaga la noticia de la "feliz" entrada de Calleja en Zitácuaro añadiendo: "... hoy es para esta ciudad un día memorable..." informó el descubrimiento de una conspiración encabezada por un sargento de pardos:

... de sus resultas están presos dos escribientes de contaduría, varios soldados de artillería y milicias y esperamos puedan ahorcarse... Se dice que el autor principal es un teniente de la Corona que estaba preso en el Castillo, y es hermano del canónigo Michelena... Si en esa ciudad y aquí no se hacen más ejemplares, me parece que estamos muy mal... ${ }^{22}$

En forma similar se consideró la expedición de Francisco Javier Mina cuando Lerdo de Tejada escribió diciendo que debían aprovecharse las ventajas que of recían las "lisonjeras" noticias de la prisión de Mina y demás "traidores" que permitirían que el comercio volviera "a su ser". 23

\footnotetext{
${ }^{19}$ Ibid., 14 junio 1814.

${ }^{20}$ Ibid., 28 junio 1814 .

${ }^{21}$ Ibid., 11 enero 1812 .

${ }^{22}$ Ibid., 18 marzo 1812.

${ }^{23}$ Ibid., 8 y 9 noviembre 1817 .
} 
Habia, por otro lado, una crítica a la falta de eficacia con la que las autoridades locales resolvian las dificultades políticas de la plaza. Ya en diciembre de 1811 era tanta la escasez de plata en el puerto de Veracruz que el gobernador debió recurrir al sector mercantil para financiar el sostenimiento de las tropas realistas. Juan Antonio comunicó la formación de una junta general en la que se expuso la necesidad de que el "pueblo" las mantuviera, designándose una comisión que buscara arbitrios integrada por Juan Manuel de Muñoz, Pedro Miguel de Echeverría, Manuel de Viya y Xivaja, José Ignacio de la Torre, José Mariano de Almanza y Francisco Arrillaga, con lo que, decía, se tendría "nuevo costeo". Más adelante, por las mismas circunstancias, la necesidad que tenían los convoyes de detenerse en Xalapa y de combatir a los insurgentes fortificados en Puente Nacional hacía que se dispusiera de parte de los caudales que conformaban las conductas, provocando el descontento de los comerciantes porteños que las esperaban con ansias. ${ }^{24}$

Para finales de 1817 la situación mercantil porteña era tan crítica, y se resentían de tal modo las dificultades cada vez más crecientes derivadas de la guerra insurgente y de la incomunicación con España, que ciertos sectores del grupo de comerciantes buscaron la manera de presionar al Consulado para exponer ante el Virrey la necesidad de abrir el puerto de Veracruz "a todos los extranjeros". Juan Antonio Lerdo de Tejada reseñó una reunión particular que celebraron los miembros de dicha corporación a la que él asistió con el deseo de "salir de semejantes enredos", y en la cual hubo 11 votos en contra del comercio libre y 5 a favor, terminando por desaprobar el decidido "empeño" de los partidarios de la propuesta. ${ }^{25}$

En términos generales, la correspondencia entre Juan Antonio Lerdo de Tejada y Manuel de Urquiaga refleja, pues, las actividades mercantiles y el sentir de un integrante del grupo de comerciantes peninsulares porteños. La información recopilada en el archivo municipal de dicha población refuerzan la visión y las inclinaciones que se han examinado hasta aquí. En junio de 1820 fue elegido síndico procurador primero y comisionado del ramo de Puentes y Calzadas, y participó en casi todas las sesiones de cabildo que se celebraron entre esta fecha y la de su traslado a la villa de Xalapa en 1821. Por el estudio de la documentación que habla de su participación en esta corporación, podría decirse que estuvo al tanto de múltiples asuntos públicos: finanzas, mejoras materiales, alquileres, arrendamientos, escuelas, impuestos, sanidad, milicias y problemas de jurisdicción entre el ayuntamiento y el gobernador jefe político. Empero, la defensa de sus intereses quedó reflejada en las exposiciones que redactó para conservar el monopolio mercantil porteño. ${ }^{26}$

Por ejemplo, no estuvo de acuerdo con la solicitud que presentó el cabildo de Cosamaloapan para suprimir los impuestos sobre sus efectos y frutos, que se utilizaban para cubrir los gastos ocasionados por el alojamiento de la tropa que los custodiaba cuando se transportaban al puerto; Juan Antonio, al igual que los demás capitulares, no encontró una sola razón por la cual los vecinos veracruzanos pagaran los gastos de dicho alojamiento, puesto que la custodia era necesaria

${ }^{24}$ Ibid. 25 diciembre 1811,16 enero 1815.

$\because$ Ibid. 18 septiembre 1817.

A Archivo Municipal de Veracruz. Actas de Cabildo, enero-noviembre 1820. Carmen Blázquez Domínguez, op. cit.. p. 8. 
para las mercancías procedentes de aquella población y no para las de la plaza porteña. Asimismo siguió oponiéndose al comercio libre y por ello se mostró contrario a la introducción de harinas extranjeras debido a que, en su opinión, afectaba a la "agricultura y a la industria coloniales".

Su posición en el contexto social y político del puerto de Veracruz a lo largo de las dos primeras décadas del siglo xix fue sólida, si bien no puede considerársele de tanta importancia como la de comerciantes mayores del tipo de Viya, Martínez, Pasquel, Murphy, etc. De cualquier manera, dicha posición se hallaba reforzada por sus vínculos con Cádiz y por sus contactos locales y familiares, entre los que sobresalen los del brigadier del Corral. El material que contiene el archivo municipal de Tlacotalpan reveló información sobre Miguel del Corral, gobernador militar de Veracruz a finales del siglo xvill, que requiere una atención más detallada por la diversidad de asuntos en los que se ocupó, entre los cuales sobresalen las determinaciones tomadas para mantener la tranquilidad pública, el control de la introducción de efectos extranjeros y la libre circulación de los productos locales entre Tlacotalpan, poblaciones circunvecinas y Veracruz. ${ }^{27}$

Podríamos resumir la figura de Lerdo de Tejada como la de un comerciante español involucrado básicamente, en esas fechas, con el comercio ultramarino; vinculado por matrimonio a una familia pudiente, partícipe en la política municipal y cuyos intereses eran afines a los de los grandes mercaderes indianos. Algunos de estos elementos paternos fueron asimilados por los hijos, sobre todo después de la muerte del padre, permitiendo su incorporación a los nuevos grupos sociales de comerciantes-empresarios: se continuó con el ejercicio mercantil dentro de un nuevo contexto marcado por la vida independiente, se mantuvieron los contactos hacia el exterior, se conservaron los lazos establecidos (amistad-familia-negocios) y se buscó participar en la política local.

El año de 1821 señaló un cambio de residencia. Los constantes trastornos provocados por las guerrillas insurgentes motivaron el abandono del puerto de Veracruz y el establecimiento de la familia en la villa de Xalapa, población muy unida a los intereses porteños y mucho más cercana al Altiplano. Hubo, pues, una mejoría económica en una etapa de crisis y transición política.

A partir de este momento, Juan Antonio, y con el tiempo los hijos (Francisco, Juan, Miguel, Ignacio), formaron parte de los procesos de cambio iniciados con la Independencia a través de alianzas políticomilitares que no respondian, en la primera mitad del XIX, a una pureza ideológica y mucho menos a la clara identificación con lo que hoy podríamos llamar partidos políticos. Establecieron relación con los grupos políticos y militares que podían o parecían poder garantizar la formación de bloques de poder, y se identificaron con la necesidad imperiosa de "modernizar" al país, de "civilizar", de alcanzar el "progreso nacional", considerando no sólo su propio beneficio, sino el beneficio de toda la sociedad. ${ }^{28}$

\footnotetext{
${ }^{27}$ Archivo Municipal de Tlacotalpan, Correspondencia, 1768-1800.

${ }^{28}$ Véase: Carmen Blázquez Domínguez, Lerdo de Tejada..., op. cit. Margarita Urias, "Manuel Escandón: de las diligencias al ferrocarril, 1833-1862", en Formación y desarrollo de la burguesía en México. Siglo XIX. México, Editorial Siglo xxI, 1981.
} 
Como han indicado algunos autores, en la mayoría de los trabajos de historiografía política del siglo XIX están ausentes los representantes del nuevo capital comercial, y a los Lerdo de Tejada casi nunca se les estudió desde ese punto de vista. En los años en que se pugnó por establecer proyectos de Estado y nación, 1821-1850, en que dominó la figura de Antonio López de Santa Anna, en que se conformaron los partidos y el ejército sirvió a los intereses de la facción que preservaba y aumentaba sus privilegios, Juan Antonio y sus hijos desplegaron actividades en comercio y política que les permitieron adquirir la experiencia necesaria para rebasar el ámbito regional, incursionar en el contexto nacional y definirse políticamente por el partido con cuyas metas coincidian sus propios intereses y aspiraciones, el liberal. ${ }^{29}$

El periodo que corresponde al establecimiento en la población xalapeña ha podido ser estudiado, al menos en parte, gracias a la documentación notarial y municipal de Xalapa. Esta villa, de clima templado y benigno, atrajo a muchos de los extranjeros que especulaban con las mercancias extranjeras y que huían del clima y de la insalubridad del puerto de Veracruz, sobre todo en los meses de calor, entre abril y agosto. Era una ciudad de paso para viajeros que subían al Altiplano, y gozó durante el siglo xvill de la prosperidad mercantil derivada de la celebración de las ferias. Con la guerra de Independencia sus actividades mercantiles decayeron y, aunque existía en ella la misma agitación política e intelectual que imperaba en la plaza porteña, continuaba siendo un punto de relevancia dentro del sistema de comunicaciones y transportes que determinaba la economía regional. ${ }^{30}$

Así, pues, Juan Antonio Lerdo de Tejada, comerciante porteño radicado en Xalapa, continuó dedicándose a la práctica mercantil de corto y largo alcance, e incluso a las actividades crediticias, logrando adaptarse a la nueva situación política que implicó la ruptura del pacto colonial gracias a sus contactos con el mercado regional, a sus relaciones internacionales y al capital familiar, al uso de circulante heredado por su cuñada, Isabel del Corral, y por su propia esposa, Concepción, de un tío comerciante gaditano, Pedro de Aycinena.

Con el "principal" disponible estableció, en noviembre de 1824 , con otro comerciante local, Mariano de la Bárcena y Gordón, una tienda de comercio "de la clase que llaman mestiza" durante un lapso de cinco años y con un capital de 12 mil pesos, 10 mil de los cuales provinieron de la mencionada herencia de su cuñada Isabel. En el mismo año, y también con capital de esta última, facilitó a Juan Priani, vinculado a otros comerciantes xalapeños de mucha fuerza como Antonio María Priani, Luis García Teruel y Bernardo Sáyago, mil pesos en calidad de préstamo. Para 1825 utilizó, de la herencia de su esposa, 10 mil pesos para la compra y venta de cinco tercios de seda en rama. ${ }^{31}$ La documentación notarial nos permite ver que, al menos hasta 1829 , fecha probable de su muerte, continuó involucrado

\footnotetext{
:Véase Carlos San Juan Victoria y Salvador Velázquez Ramírez, "La formación del Estado y de las políticas económicas (1821-1880)", en México en el siglo xix (18211910). Historia económica y' de la estructura social. 1, México, Editorial Nueva Imagen. 1983.

"Carmen Blázquez Domínguez, Lerdo de Tejada. ... op. cit. p. 12-13.

"ANX. Protocolo 1824, 19 noviembre y 10 diciembre 1824; Protocolo 1825, 6 agosto 1825: Protocolo 1827, 13 septiembre 1827.
} 
en asuntos mercantiles, crediticios y de representación, tanto en el puerto de Veracruz como en Xalapa y en la ciudad de México. ${ }^{32}$

\section{Continuidad de la praxis familiar}

Después de su fallecimiento, tres de sus hijos continuaron la tradición paterna: Francisco, Ignacio y Miguel, e intentaron mantener la red mercantil ya creada. En 1831 su viuda, Concepción Corral y Bustillo, solicitó y obtuvo de la Legislatura veracruzana que su hijo Miguel, entonces de 19 años, manejara sus intereses. ${ }^{33}$ En 1836 este último, en unión de su hermano Ignacio y junto con Tadeo Ortiz, formaron una compañía sobre el manejo de una "tienda de pulpería" por un lapso de cinco años y con un capital de 3 mil pesos. Entre 1839 y 1840 los tres hermanos mencionados mantenían casas mercantiles de regular importancia en México, Xalapa y Veracruz, sostenían vínculos crediticios hacia el exterior (Cádiz), giraban libranzas e incluso utilizaban a su vez el capital familiar para el financiamiento de sus actividades. Francisco, casado con una prima suya, Concepción Corral y Vallejo, manejó la parte de herencia que le correspondía a esta última por la muerte de su padre, Francisco del Corral, que a la vez era tío suyo. ${ }^{34}$

Por lo que se refiere a la política local, entre 1829 y 1846 Francisco incursionó con bastante éxito en ella. Formó parte de la corporación municipal que funcionó en 1841 , y en 1842 resultó designado jefe político. Para 1846 fue nombrado encargado de la aduana marítima de Mazatlán, cuando su hermano Miguel ya se encontraba establecido en la ciudad de México, dejando el manejo de sus asuntos a Bernardo Sáyago, otro comerciante-propietario-empresario de gran importancia regional. ${ }^{35}$

Las actividades políticas del hermano mayor no significaron la definición política de la familia en fechas en que éstas, insistimos, no estaban dadas, de manera que no es posible afirmar que adoptaron posiciones claras en relación con los acontecimientos políticos que enfrentaron en la primera mitad del siglo XIX; es más probable indicar que actuaron en defensa de sus intereses. Y quizá esta circunstancia explique sus relaciones con sujetos que posteriormente militaron en bandos opuestos o al margen de ellos, como es el caso de Manuel Escandón, o los vínculos que mantuvieron con la familia de Antonio López de Santa Anna.

Creemos que la similitud entre las actividades de Juan Antonio Lerdo de Tejada y los tres primeros hijos, Francisco, Ignacio y Miguel, es manifiesta en ciertos aspectos. También podemos señalar que el padre los dotó de una red de contactos no sólo mercantiles, sino políticos y familiares, que permitió con el tiempo desplegar actividades paralelas en política, comercio y diversificación empresarial. Miguel y Sebastián iniciaron, a partir de 1847 el primero, y de 1857 el segundo,

${ }^{32}$ Ibid., Protocolo 1823, 13 mayo 1823; Protocolo 1826, 6 junio y 30 septiembre 1826; Protocolo 1829, 26 enero y 2 abril 1829.

${ }^{33}$ Colección de leyes $y$ decretos del gobierno del estado de Veracruz, vol. 1831, p. $96-97$.

${ }^{34}$ ANX, Protocolo 1831, 13 agosto 1831; Protocolo 1833, 14 junio 1833; Protocolo 1836, 30 julio 1836; Protocolo 1839, 23 y 30 marzo y 7 junio 1839; Protocolo 1840,23 enero y 21 marzo 1840.

${ }^{35}$ Archivo Municipal de Xalapa, Actas de Cabildo, abril-agosto 1841, agosto 1842. Carmen Blázquez Domínguez, Lerdo de Tejada. ... op. cit., p. 14-16. 
carreras políticas entonces sí definidas claramente por la facción liberal, mientras otro hermano, Ángel, continuó realizando operaciones mercantiles y se mezcló en inversiones de otro tipo, como la instalación de ferrocarriles urbanos y de vapores en los lagos del valle de México. ${ }^{36}$ 